\title{
Haemochromatosis presenting as congestive cardiomyopathy and responding to venesection
}

\author{
C. Skinner and A. C. F. Kenmure \\ From Aberdeen Royal Infirmary, Foresterhill, Aberdeen
}

A case of primary haemochromatosis presenting as an obscure congestive cardiomyopathy in a young man is described. No other clinical evidence of haemochromatosis was present. Substantial improvement followed venesection. The cardiac manifestations of haemochromatosis are reviewed. It is suggested that the diagnosis must be excluded in any male patient with cardiac disease of undetermined aetiology.

Cardiac involvement in primary haemochromatosis is well documented and is, characteristically, a feature of cases presenting in childhood (Perkins et al., I965) or early adult life (Petit, 1945). Nevertheless, it is unusual for the presenting symptoms to be cardiac and the underlying condition is usually suspected clinically, due to the presence of one or more of the other typical clinical features of haemochromatosis, such as skin pigmentation, testicular atrophy, sparse facial and pubic hair, or diabetes mellitus (Petit, 1945; McAllen, Coghill, and Lubran, 1957; Evans, 1959; Grosberg, 1961 ; Perkins et al., 1965; Aronow, Meister, and Kent, 1969). However, in one of the cases described by Lewis (I954), such features were absent and the correct diagnosis was only established at necropsy following death from congestive heart failure. We wish to report a further case presenting as congestive cardiomyopathy, without other clinical evidence of haemochromatosis, and showing substantial improvement after repeated venesection.

\section{Case report}

A 32-year-old carpet fitter was admitted to Aberdeen Royal Infirmary in February 197I with a three-month history of progressively severe breathlessness and palpitations on exertion. He had been unable to work for
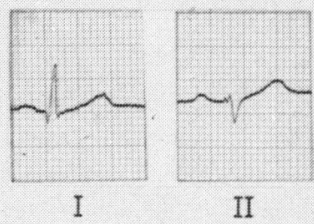

II

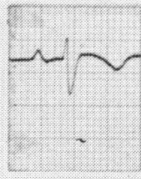

V1

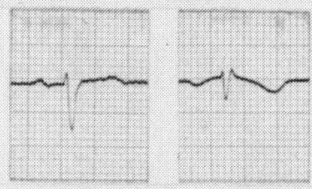

$a V R$

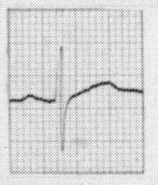

V4

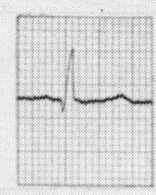

oVL

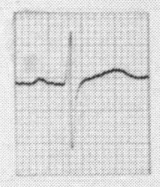

V3

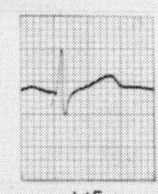

V5
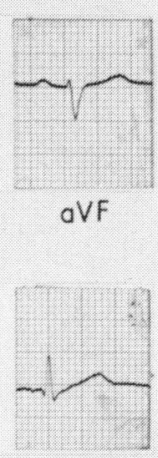

V6

FIG. I Electrocardiogram showing left axis deviation, right atrial hypertrophy, and an intraventricular conduction defect. 
three weeks preceding admission on account of these symptoms. There was no history of joint pains or abdominal symptoms, libido was normal, and he had observed no disturbance of facial or body hair growth. His alcohol intake was not excessive. On examination his general condition was good. Skin texture and colour were normal. Facial, axillary, and pubic hair were present and the testes were of normal size. Liver and spleen were impalpable. The pulse was regular at a rate of 80 a minute and was of small volume. Blood pressure was I08/80 $\mathrm{mmHg}$ and jugular venous pressure Io $\mathrm{cm}$, with prominent ' $a$ ' waves. The apex beat was in the fifth intercostal space on the anterior axillary line and was normal in character. A slight left parasternal heave was also noted. Heart sounds were normal with no murmurs. There was no peripheral oedema. The electrocardiogram (Fig. I) showed left axis deviation, right atrial hypertrophy, and an intraventricular conduction defect. Chest $x$-ray (Fig. 2a) revealed gross cardiac enlargement with clear lung fields and, at fluoroscopy, generally poor cardiac pulsations were observed. Right heart catheterization showed a right ventricular pressure of $35 / 9 \mathrm{mmHg}$, normal right atrial pressures $(a=10$, $x=6, v=9, y=7$ ), a main pulmonary artery pressure of $33 / 12 \mathrm{mmHg}$, and a mean pulmonary capillary pressure of $14 \mathrm{mmHg}(a=15, x=12, v=15, y=12)$. There was no evidence of a right-sided valve lesion, left-to-right shunt, or pericardial effusion.

Numerous biochemical and serological tests were performed in an attempt to defect an underlying cause of cardiomyopathy. The results of these investigations showed no significant abnormality apart from the serum iron which was raised at $305 \mu \mathrm{g} / \mathrm{r} 00 \mathrm{ml}$, with a total ironbinding capacity of $349 \mu \mathrm{g} / 100 \mathrm{ml}$. Six-hour postdesferrioxamine urinary iron excretion was $8.6 \mathrm{mg}$, indicating greatly increased body iron stores (Rosen and
Tullis, I966). A needle biopsy specimen of liver showed the histological features of haemochromatosis with heavy iron deposition in hepatocytes, sinusoidal-lining cells, and cells within areas of portal fibrosis traversing the hepatic parenchyma. A skin biopsy also showed the features of haemochromatosis. Serum aspartate transaminase was raised at $36 \mathrm{I}$.U./1. but conventional liver function tests, including bromsulphalein excretion, were otherwise normal. Blood count was normal apart from a reduced platelet count of $101,000 / \mathrm{mm}^{3}$. An oral glucose tolerance test gave a borderline diabetic result, but intravenous glucose tolerance testing yielded a normal increment index. Twenty-four hour urinary I7hydroxy-corticoids were normal while 17 -ketosteroids were low at $2.6 \mathrm{mg}$ (normal range $8-24 \mathrm{mg} / 24 \mathrm{hr}$ ).

Over a period of 4 weeks in hospital his symptoms improved with rest alone and jugular venous pressure fell to normal levels. Chest $x$-ray appearances, however, remained unchanged. After liver biopsy he developed paroxysmal atrial flutter with 2: I atrioventricular block and a ventricular rate of 150 a minute. This caused him no distress, and spontaneous reversion to sinus rhythm occurred after 12 hours. He was discharged home on no drug treatment, and weekly venesection was started with removal of $500 \mathrm{ml}$ blood on each occasion. Complete abstention from alcohol was advised. He steadily improved and ro months after beginning of venesection, by which time 181 . blood (approximately equivalent to $9 \mathrm{~g}$ iron) had been removed, he was able to carry out normal activities and returned to full-time work. Chest $x$-ray at that time showed that significant reduction in cardiac size had occurred (Fig. 2b). Electrocardiogram was unchanged. Venesection will be continued weekly until his iron stores are depleted and, thereafter, sufficiently often to maintain a mild hypochromic anaemia and prevent reaccumulation of iron.

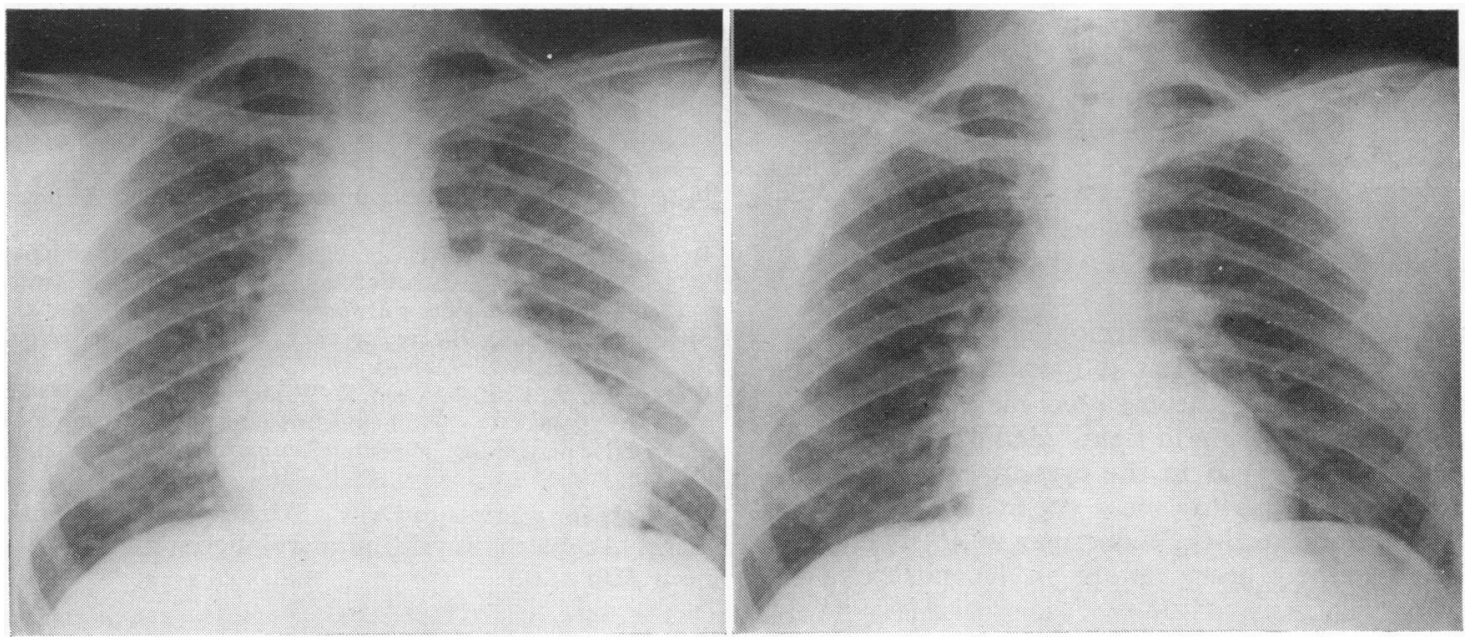

FIG. 2 Chest X-rays: (a) at the time of presentation showing gross cardiomegaly; (b) after Io months' venesection, showing reduction in cardiac size. 


\section{Comment}

Cardiac failure is the cause of death in over a third of all cases of haemochromatosis and in over a half of those cases in which death occurs in the third and fourth decades of life (Finch and Finch, 1955). For this reason, and because the condition is potentially remediable, a diagnosis of haemochromatosis should be positively excluded in every male patient with cardiac disease of obscure aetiology.

It is clear that the diagnosis cannot be confidently excluded on clinical grounds alone. As in the present case the serum iron level is characteristically increased in haemochromatosis with about 90 per cent saturation of the serum total iron-binding capacity (Sherlock, 1968). This provides a useful screening test for the condition which, though not infallible, has the virtue of simplicity. A further pointer to excess body iron stores is the demonstration of excess urinary iron excretion after injection of an ironchelating agent. In the present case iron excretion was vastly above the normal range quoted for the method (Rosen and Tullis, 1966). The most satisfactory method of establishing a diagnosis of haemochromatosis is by liver biopsy (Sherlock, 1968), but this may be hazardous if liver function is seriously disturbed due to cirrhosis or venous congestion secondary to right heart failure. Certainly the procedure cannot be regarded as a screening test.

The cardiac manifestations of haemochromatosis are emphasized by the French who recognize an 'endocrino-hepato-cardiaque' syndrome. The French literature on the subject is reviewed by Petit (1945). Haemochromatosis affecting the heart typically produces diffuse cardiac enlargement, with progressive biventricular failure (Lewis, 1954). Rhythm disturbances are well described, especially atrial arrhythmias (Lewis, 1954; Evans, 1959) and atrioventricular block (Petit, I945; Aronow et al., 1969). Ischaemic chest pain may also occur in the absence of significant coronary artery disease (Petit, 1945). Constrictive pericarditis may be closely mimicked and exploratory thoracotomy has been performed in at least one case (Wasserman et al., 1962). Some electrocardiographic abnormalities have been described but no specific pattern is recognized. Cardiac catheterization may show a slight, nonspecific increase in right-sided pressures (Aronow et al., 1969) as in the present case and a high end-diastolic plateau may occur, suggesting constrictive pericarditis (Wasserman et al., 1962).

Established heart failure in haemochromatosis responds poorly to conventional treatment with rest, digitalis, and diuretics, and death usually occurs within a year of the onset of failure (Bothwell and Alper, 195I; McAllen et al., 1957). Such a gloomy prognosis, however, does not take account of the effect of therapeutic depletion of body iron, and there have been several encouraging reports of substantial and sustained improvement with repeated venesection (McAllen et al., 1957; Grosberg, I96I ; Perkins et al., 1965). The value of this form of treatment is borne out by the present case in which, a year after initial presentation, the patient remains active and well on a regimen of venesection alone without supportive digitalis or diuretic therapy.

We wish to thank Dr. P. Brunt for performing the liver biopsy.

\section{References}

Aronow, W. S., Meister, L., and Kent, J. R. (I969). Atrioventricular block in familial hemochromatosis treated by permanent synchronous pacemaker. Archives of Internal Medicine, 123, 433.

Bothwell, T. H., and Alper, T. (I95I). The cardiac complications of haemochromatosis: report of a case with a review of the literature. South African fournal of Clinical Science, 2, 226.

Evans, J. (1959). Treatment of heart failure in haemochromatosis. British Medical fournal, I, 1075.

Finch, S. C., and Finch, C. A. (1955). Idiopathic hemochromatosis, an iron storage disease. Medicine, 34, 381.

Grosberg, S. J. (I96I). Hemochromatosis and heart failure: presentation of a case with survival after three years' treatment by repeated venesection. Annals of Internal Medicine, 54, 550 .

Lewis, H. P. (1954). Cardiac involvement in hemochromatosis. American Fournal of the Medical Sciences, 227, 544.

McAllen, P. M., Coghill, N. F., and Lubran, M. (1957). The treatment of haemochromatosis with particular reference to the removal of iron from the body by repeated venesection. Quarterly fournal of Medicine, 26, $25 \mathrm{I}$.

Perkins, K. W., McInnes, I. W. S., Blackburn, C. R. B., and Beal, R. W. (1965). Idiopathic haemochromatosis in children: report of a family. American fournal of Medicine, 39, II8.

Petit, D. W. (1945). Hemochromatosis with complete heart block. American Heart fournal, 29, 253.

Rosen, B. J., and Tullis, J. L. (1966). Simplified deferoxamine test in normal, diabetic, and iron-overload patients. fournal of the American Medical Association, 195, 261.

Sherlock, S. (1968). Diseases of the Liver and Biliary System, 4th ed. Blackwell, Oxford.

Wasserman, A. J., Richardson, D. W., Baird, C. L., and Wyso, E. M. (1962). Cardiac hemochromatosis simulating constrictive pericarditis. American fournal of Medicine, 32, 316.

Requests for reprints to Dr. C. Skinner, Ward 3, Cardiology, Aberdeen Royal Infirmary, Foresterhill, Aberbeen AB9 2ZB. 